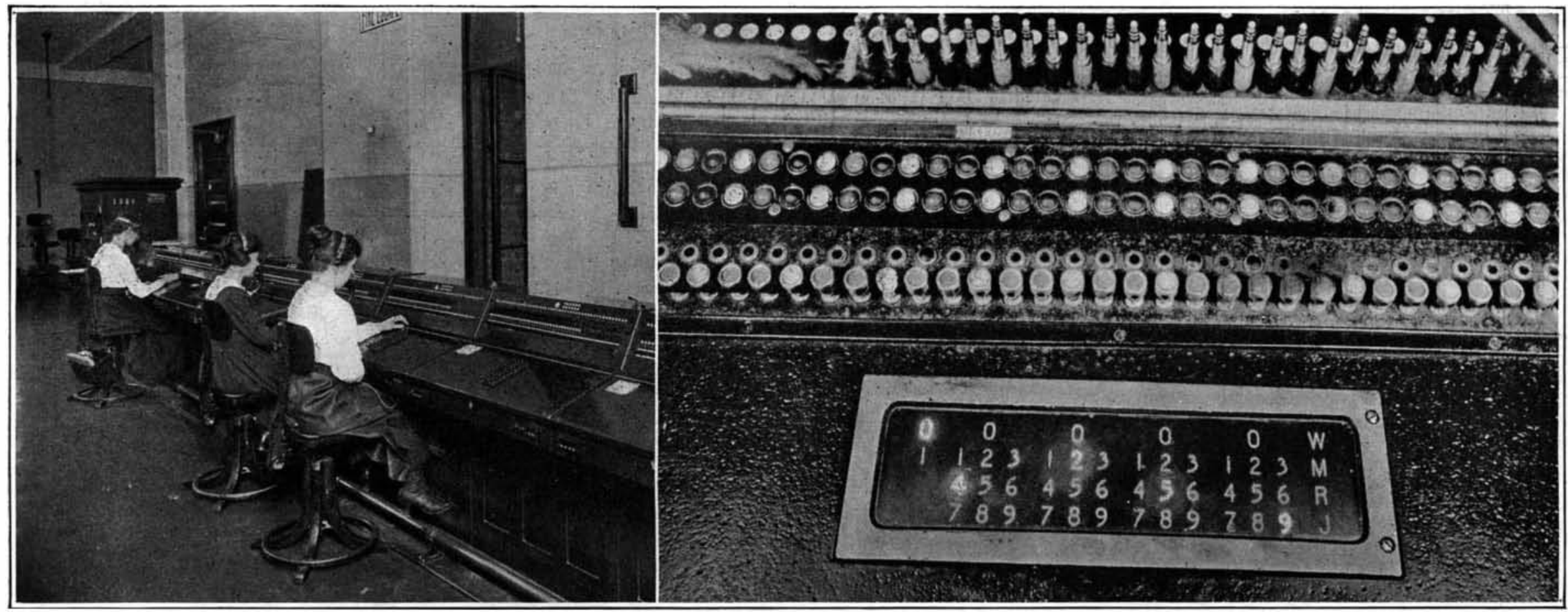

Left: Typical installation of "cordless B" pnsitions in a machine switching office. Right: Call indicator at an incoming trunk positinn in a manual office showing number 4259 displayed. Two of the clever dodges whereby the automatic telephone is enabled, pending its complete installation throughout the city, to work with the manual offices

\title{
The Mechanical Hello Girl
}

\section{An Automatic Telephone Switchboard That Can Take Care of the Busiest Exchange}

\author{
By H. A. Mount
}

THE automatic telephone is not new. Efforts to 1 build a telephone system in which any subscriber could be automatically connected with any other desired subsicriber without the aid of a human hand, began in 1879 , only three years after Dr. Bell produced the telephone.

But an automatic telephone exchange in a big city, such as New York, where there are in the neighborhood of a million telephone stations served by 100 central offices is decidedly new and of great significance. In the years between 1879 and the present many inventors have tackled the problem and there have been many s.sstems of automatic telephony invented. Automatic telephones have been used successfully in towns and into the big centers of population like Chicago, Philadelphia or Boston presented obstacles which seemed well nigh insurmountable.

Where a community is served with a single centra rffice or two or three central offices the engineering problem was comparatively simple. A system had to be devised which merely made it possible for any subscriber in the system to reach any other subscriber.

But in New York not only must each of the $1,000,000$ subscribers be able to reach any other, but due to the large area involved, many of the calls involve extra charges, which means that the must be supervised, timed and ticketed. Then there are the following general classes of service demanded by the pub(a), offAdd to this single party two party and four party service and picture " densely populated surrounding country with sereral hundred towns and cities from which come and to which go thousands of messages each day, all of which have to be supervised, timed and recorded

That an automatic telephone system capable of doing all these things and many others could be devised seems little

short of marvelous. And yet the biggest problem of all was not in doing these things, but in devising a system which would operate in harmony with the existing manual central offices.

It will be seen that the task involved in changing to automatic telephones in a large city is stupenuluus and it would be a phrsical impossibility to convert place gradully, one changing to automatic switching, until the whole job is accom plished. The change must be made without interrup-

tion of service and for a period of some years the new automatic apparatus must work in harmony with manual apparatus.

The first part of New York's automatic system is now in operation and the whole city is to be converted to automatic switching as fast as apparatus can be manufactured and installed. The process will be so slow, however, that telephone officials say they will not have to discharge a tor replaced by an auswitchboard. Due to bor turnover, on the the company tinually to tinually to prators. The stantly being and it is the telephone en in $1950 \mathrm{New}$
THE telephone a complexity could hardly have foreseen gling to reproduce the human of a wire. The suggestion that this oast network of wires and performed automatically seems at first blush preposterous. But every day it is harder to recruil the army of operators needed for the manual exchanges. the operator, but merely of getting along with the operators that can be obtained. Largely on this account a determined effort has been made to apply automatic telephony to the large and busy exchange as well as to the small and comparatively idle ones; and incredible as it may seem, this has been a complete success. We may look forward with certainty to the day when any two instruments in New York City may be connected without the intermediate agency of any human operator. This is the story which Mr. Mount presents to us here.-THE EDITOR. until it reached the called line on a very much smaller multiple

The first system to find any commercial application makes use of this fundamental trunking principle. The switches are the "up and around" type with 10 vertical and 10 rotary steps, each switch accommodating 100 lines or 100 trunks. A dial with the 10 digits 1 to 0 is provided at each subscriber's station. The subscriber in calling manipulates this dial. This sends impulses to the switches, which cause them to build up the connection desired.

For example, when a subscriber calls a four digit number, as 9653 in a 10,000 -line system, the first movement of the dial by the calling subscriber will send nine impulses to the central ofice corresponding thousandths digit, and the switch under direct control of these impulses will step up nine times and extend the line to another switch which serves the ninth thousand. The next movement of the dial will send six impulses and this will cause the switch of the ninth thousand to step up six times and extend the line to a switch which is capable of reaching the hundred lines of the sixth hundred of the ninth thousand. The next movement of the dial will send five impulses to correspond to the tens digit and will cause this last switch to step up five times. The last movement of th dial will send three impulses which will cause this same switch to take three rotary steps and thereby complete the connection of course the system is more complicated than this because there is machinery for automatic ringing, for giv ing busy signals, and the like. But most of the automatic systems in use follow these general lines. There have been many minor improvements in this system but the general principle has not bees altered

More recently there has been devised the "automanual" system, which as its name implies, includes some of the fea- he at least 2700,000 stations served by 225 offices. single exchange to deal with and only a few subscribers. The first machine switches produced had a separate switch for each line, so arranged that it could find and connect directly with any other line in the exchange. The long adherence to this plan was probably one of the principal causes for failure of these early systems. The first systems to succeed to any whereby the calling line was extended link by link The first makers of automatic telephones had a marked extent made use of a scheme of trunking tures of both the implies, includes some of the feathis system the subscriber calls central and gives his number in the usual fashion. But Central sets up the number on a switchboard with very much the appearance of an adding machine and the switching is done automatically.

There were several reasons why these systems, although used successfully in many places, could not be adapted to the needs of large cities. It was found that too great a mass of machinery and equipment would be needed and to meet this objection a new type of switch 
had to be devised. The basic necessity of having a large number of trunks in one group added another difficulty-the system could not be laid out on a $10 \times 10$ or decimal basis. At the same time it was obviously desirable that the calling device be operated by the subscriber on a decimat basis. With a large number. of trunks in one group, it was found that there was not suficient time between one there was not suficient time between one set of impulses and the next to permit thr switches to hunt and find an idle path or

To meet these and other objections the "sender" was devised and it is declarer to be the greatest single advance in the art since the selector switch. Instead of controlling the switches directly by the impulses from the subscriber's dial, these impulses are received and literally storecl up by the sender. The sender then alup by the sender. The sender then alsired point and then stops them by removing their driving power. This permits the usual decimal system of numbering, but the sender can be arranged to translate these decimal impulses to any desired non-decimal system, permitting the most advantageous arrangement of wiring and switches to meet any given con:

dition. It permits the elevators or switches to hunt o.er any number of trunks in a group without any reference to the speed of the calling device. This fact permits the building of rugged power-driven switche which can be operated at their best speed on circuit local to the central office. It solves the most serious problems of the large cities by permitting the most economical arrangement of trunks outgoing from any uffie; it allows trunk groups to be made larger or place to another to mett changing conditions. place to another the menst economical layout can be used without fea that future expansion in any direction will be blocked.

It must be remembered, however, that the transition period in a large city extends over a number of years and during at least half of this time most of the calls would originate in manual offices. One of the chief prollems to be met was finding a satisfactory method problems to be met was finding a satisfactory metho of sending calls from manual offices to mechanical

Three successful methods of handling service from manual to mechanical offices have been worked out, each hest suited to a certain condition. In the simplest of these, the manual operator is provided with a dial similar to the subscriber's dial and when she receives call for a mechanical station she dials it for the subscriher, having first "plugged in" on an idle trunk line.

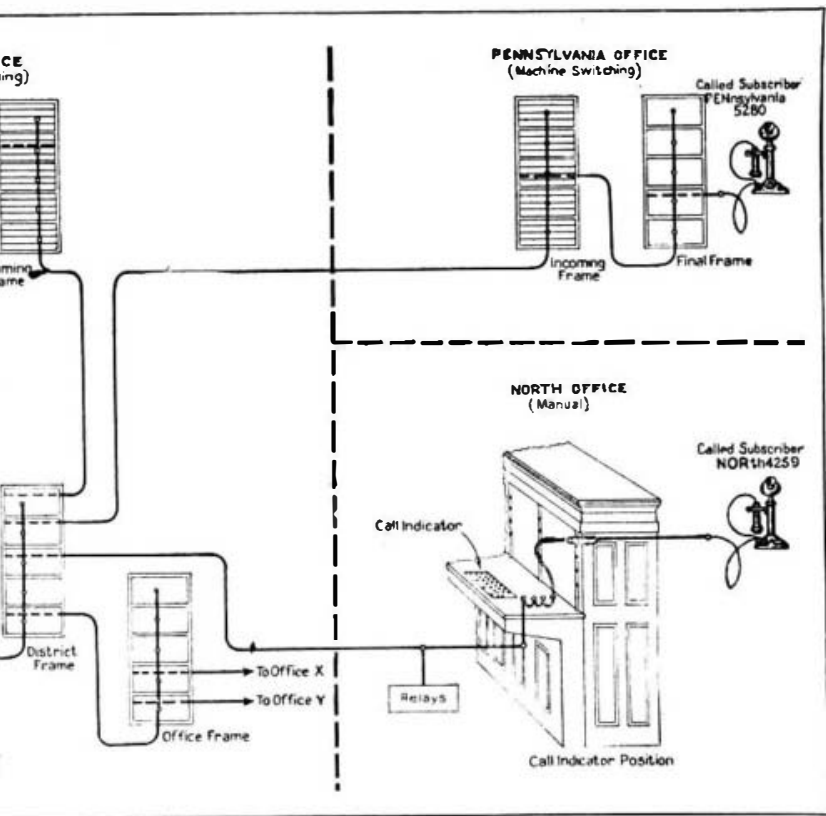

howing progress of a call from an automatic subscriber to another automatic instrument or to a manual-station subscriber

The advantage of this system is its low first cost but it has the disadvantage that where the number of calls is large it slows down the operator. It will be used only in small cities where traffic is light.

Another is called the "key indicator" plan, and permits the manual operator to complete a call to a mechanical office very speedily without the aid of any other operator. When the subscriber gives the number lesired, if it is in a mechanical office the operator esired, if it is in a mechanical office, the operator detrunk line is automatically selected for her and indi"ited by the flashing of a small lamp. She "plugs in" "ated by the flashing of a small lamp. She "plugs in" on this line, having depressed the digits of the desired
subscriber's number on a 10-button "numerical key" with which she is provided. A "sender" which has been attached automatically proceeds to guide the connections in the distant mechanical office. This plan is to be used in offices where it is proposerl to retain the manual equipment for a number of years, as it involves a large cost and extensive changes of eouipment in the manual office.

The third plan and the one to be quite frequently used is the scheme of using "cordless B" operators in the mechanical offices. The plan contemplates that the call will come in to the manual switchboard in the usual way and that the operator will handle the call as though it were to another manual office. At the incoming end, the "cordless B" operator will receive the number and will set up the number on the keys before her. A "sender" is provided to receive and register this number and to cause the desired line to be found and rung. This plan has the advantage that no changes are necessary in the manual office.

Calls from a mechanical to a manual office are always handled in the same manner. The manual operator has before her a "call indicator" consisting of a table of figures, any one of which can be illuminated by lights beneath them. The incoming call is indicated in the usual manner but instead of having the subscriber repeat the number wanted, it is set up on the "call indicator" by the illuminating of the proper figures. Thus so far as the full mechanical subscriber is concerned a call through a manual office appears to him the same as a call to another subscriber in his office. The operator then puts through the call in the usual manne.

In fact, the progress of a call through i full mechanical system is parallel in a striking way to that of a call through the manual system with which we are f:miliar and it may make the function of the apparatus more clear if we consider the similarity. When a subscriber in a manual system removes his receiver to make a call, he causes the line relay at the central office to pull up and light a lamp associated with an answering jack. An operator takes up the answering plug of a cord pair, plugs in and answers. In a full mechanical system the sul,scriber removes his receiver, causing his line reliny to pull up but instead of lighting a line lamp, it applies current to a row of contacts on the "line finder bauks" anc starts an "line finder" upward in search of this row of contacts. When the line finder reaches his contacts it is caused to stop hy having its driving power removed.

Thus there is a marked similarity between the : $1 \mathrm{n}-$ swering jack and the line finder contacts of the line finder bank; between the line finder and the answering "ord; and between the operator finding and plugging in to. an answering jack and the line finder finding and uttaching itself to the contacts on the bank this, in the manual system, the operator, after plugging in, throws a listening key and she notifies the subscriber she is ready to receive his order by saying "number, please." In the mechanical system, the "line finder" has associated with it a "sender selertor" which proceeds to find and attach an idle "sender" during the period that it is finding the calling subscriber's line. The "sender" notifies the calling sub(Continurd on page 51)

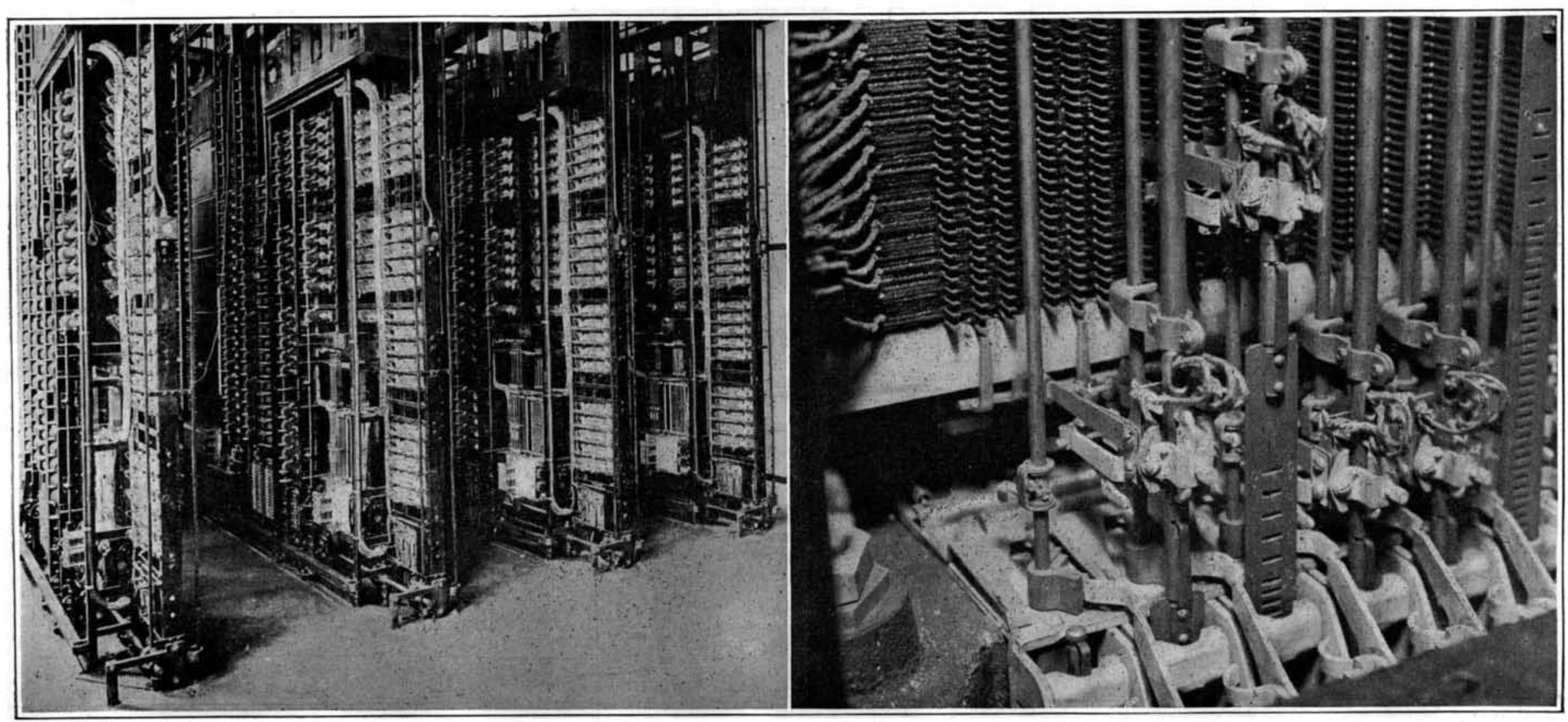

Left: General view of the installation for automatic switching. Right: Selector trame, showing details of multiple bank, multiple brush, and part of control mechanism

The apparatus that makes automatic telephony a success in the busiest exchanges 


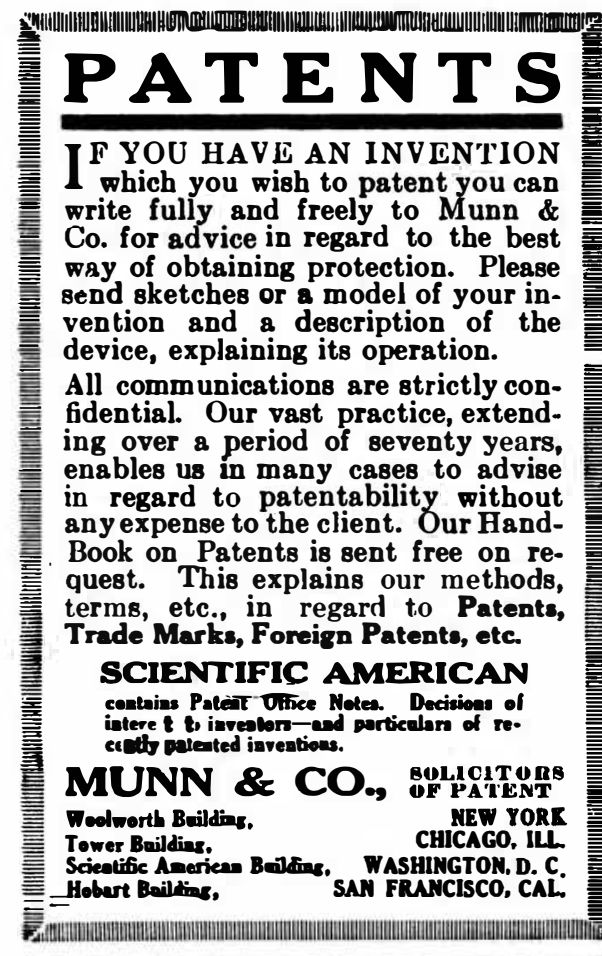

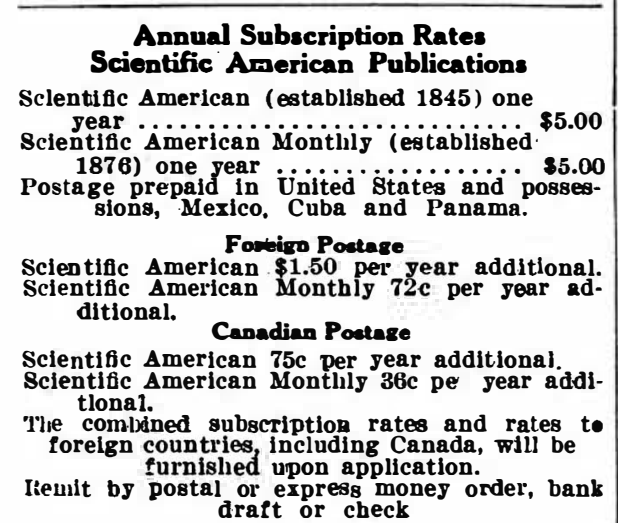

Classified Advertisements

Adiertlsthg in this column $18 \$ 1.00$ a line.
No less than four nor more than 12 lines nccepted. Count seven words to the line
nrders must be accompanied by a remittance.

BUSINESS OPPORTUNITIES

SUBST ANTIAL Manufacturing Corporation want
apable men to establish branch and manage salesmell capable men to establish branch and manage salesmell.
8zo0 to 81500 necesery. Will allow expenses to Balti-
more us explained. Address, Treasurer, 416 N. Howard more as explained.

AGENTS WANTED

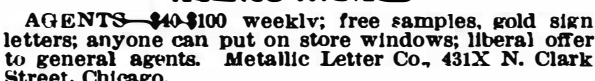

FOR SALE
AN Important lot of black Nickeloxide mixed with
fat oll, proportlon 1 to 3 , for sale. Please send offers to

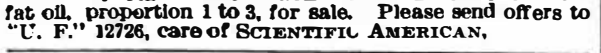
HELP WANTID
PA TENT Oofce Draftsman. State experience and
salary desired. Munn \& Co., 233 Broadwas, New York
Clty. WANIED

PEFRACTOR, 4 inch or larger, of standard make.
equatorlally mounted with circles. F. H. Chandler,
Belgrade Lakes, Maine. WANTED

THE exclusive manufacturing rights of some ma-
hine, device, or article in the metal line patented or therwse. by one of the most completelv equipped
manufacturng plaints in Indiana. Address W. F. M.--
P. O. Bor No. 263, Bedford, Indiana.

For the Highest Prices ond us false teeth, jewelry, platinum, diamonds, watches, old go!d, sil-
ver, War Bonds and Etamps. Cash by return mail. Goods returned in 10 days if you're not satisfied.
Ohio Smelting \& Refining Co., 234 Los Eleveled, Obio IDEA S FOR IN VENTORS INVENTORS UNIVERSAL EDUCATOR

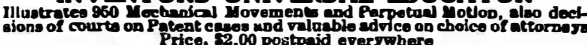

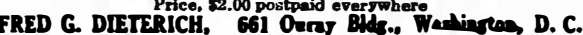

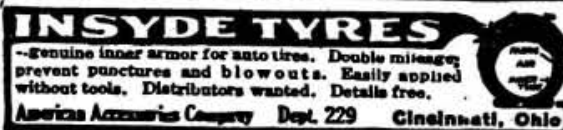

Hudson River Night Lines

Daily from Pier 31. N. R., at Desbrosea St., week-

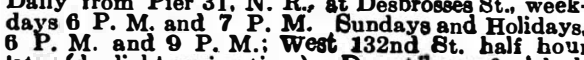
later (daylight saving time). Due Albany 6 o'clock
following morning, Troy, 7.15 A. M. Direct rail academy is a fult-size Deisel oil engine, aw to show how every part functions. The firing, scavenge and intake in the cylinder is illustrated oy colored lights automatically operated.

It has been found that by the use of models instead of drawings or photographs the task of explaining a mechanism to the student is much simplifed. Other nautical schools and in fact, schools of all kinds, have followed the Fead of the Naval Academy in using models.

The motorist now can buy models made of cardboard and metal which show him the exact function of every piece of his motor car. In fact, any attempt to catalogue the varied practical uses to which models are put must end in the approved sale-bill style "and other uses too numerous to mention."

The foregoing names some of the more important uses, but overlooks perhaps the most common-that of employing models in the developing of patents. The U. S. Patent Office formerly required that a model be submitted before patent papers were granted. But this practise was pers were granted. But this practise was discontinued after thousands of models
had accumulated and finding storage space had become a problem. But every American citizen over the age of ten years has tucked away somewhere a model of "my invention."

\section{The Mechanical Hello Girl}

(Continued from page 41)

scriber it is ready to receive his order by giving him a distinctive buzz called a "dial tone"

As the next step in the manual operation the calling subscriber gives his order verbally to the operator. In the mechinical system the calling subscriber dials lis order to the sender by pulling the letto:s and numerical digits of the number red, in succession.

Assuming that the call is for another subscriber in the same office, the maurual operator gives the desired number to " $B$ " operator in her own office over the call wires, gets a trunk assigned anc extends the calling line to the " $B$ " operator by plugging the calling corl of the pair she has used in answering into the outgoing trunk leading to the " $\mathrm{B}$ " pws: tion. The mechanical "sender," upon re ceiving the office code letters from the subscriber dial, recognizes their significance and causes the "district sclector" (elevator), which is definitely tied to the line finder previously used, to start uy and select an idle path or trunl- leadin an "incoming selector" (elevator) in the same office. The analogy is evident between the "calling cord" of the manuil system and the "district selector" of the mechanical, as well as the manual ourgoing trunk multiple jacks which terni nate at the "B" operator's nosition 10 the district selector banks which terminate incoming selectors on the incoming frame.

The "B" operator locates the desirol subscriber's number in the multiple before her by first locating the hundred, then the strip, then the particular line She then tests the line to see if it is busy. If it is not she inserts the incoming trunk into the multiple jack and ringing is started automatically. If the line had been busy, she would have inserted the trunk plug into a "busy back" jack. The mechanical step corresponding to all this is when the "sender" causes the incoming selector. to locate the group of trunks leading to the particular 500 lines in which the desired number is located. This causes a non-busy trunk to be selected and then causes the "final select or" (elevator) on the end of that trunk to locate the hundred, then the ten and finally the particular unit line desired. The "final selector" tests the line to see if it is busy, and if it is not establishes the connection. Ringing is started automatically. If the line is busy the connec-

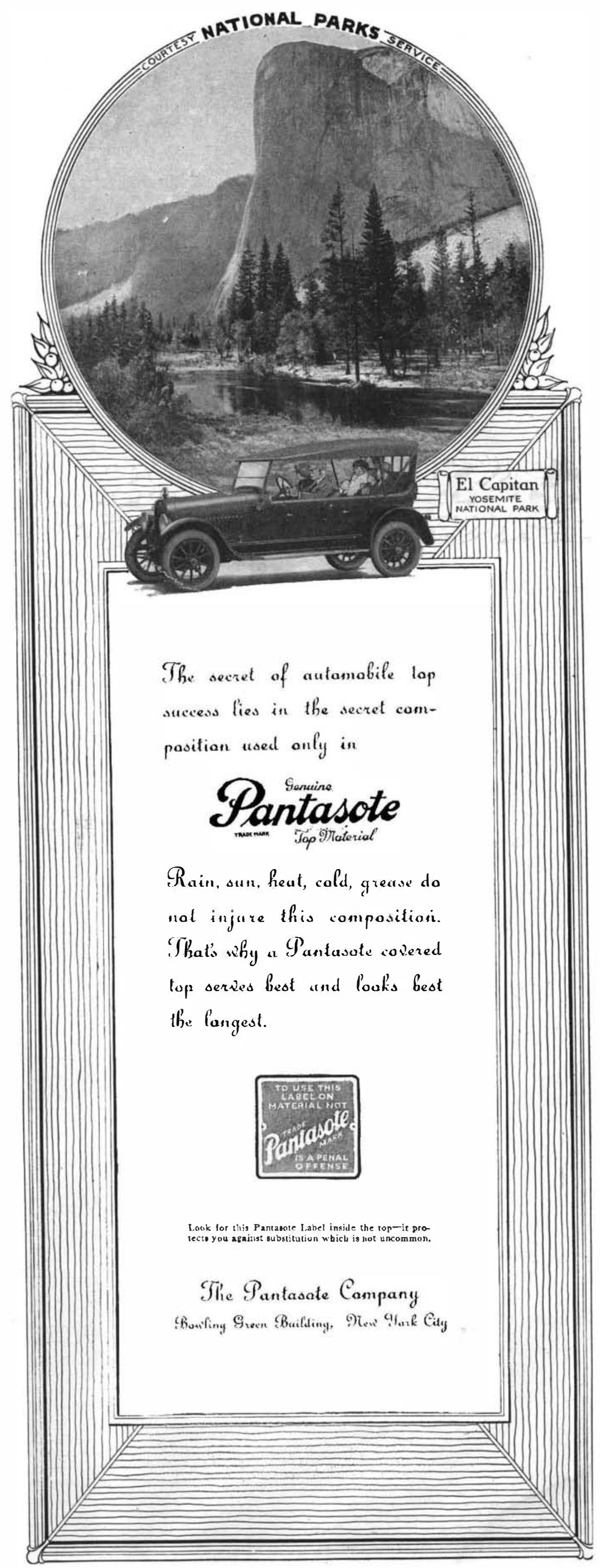


